\title{
Basin-scale variability in the Labrador Sea from TOPEX/POSEIDON and Geosat altimeter data
}

\author{
Guoqi Han and Moto Ikeda ${ }^{1}$ \\ Coastal Ocean Sciences, Department of Fisheries and Oceans, Bedford Institute of Oceanography \\ Dartmouth, Nova Scotia, Canada
}

\begin{abstract}
The TOPEX/POSEIDON altimeter data and the Geosat altimeter data from the Exact Repeat Mission (ERM) have been analyzed to show the basin-scale features of annual sea surface height anomalies in the Labrador Sea. A complex empirical orthogonal function (CEOF) analysis is used to extract spatial and temporal patterns of altimetric sea surface height anomalies. The analysis of TOPEX/POSEIDON data has revealed that the first eigenmode has an annual variation with amplitudes of $\sim 5 \mathrm{~cm}$, positive in summer and negative in winter. The Geosat data analysis implies similar results but shows only the sea surface height variabilities relative to those of the subtropical gyre circulation and the North Atlantic Current due to an orbit error correction. The steric height anomalies of the climatological monthly-mean Levitus data and the sea surface height anomalies of a wind-driven barotropic model are also analyzed using the CEOF technique. The annual cycle in the Levitus data, dominated by thermal expansion, has an amplitude of $\sim 4 \mathrm{~cm}$ and is nearly in phase with the TOPEX/POSEIDON data. The wind-driven annual signal is approximately in phase with the TOPEX/POSEIDON and Levitus data, but its amplitude is less than $\sim 1 \mathrm{~cm}$. A correlation analysis suggests that the basin-scale features deduced from TOPEX/POSEIDON data are dominated by the steric height variability of the Levitus data, supplemented to much less extent by the wind-driven response of the barotropic model. The Geosat results are found to represent the steric effect only. It is modified by the orbit error correction so much that the phase changes by $180^{\circ}$.
\end{abstract}

\section{Introduction}

The Labrador Sea has a broad cyclonic gyre circulation bordered to the west by the Labrador Current, to the south by the most northerly branch of the North Atlantic Current, and to the east by the West Greenland Current [Lazier and Wright, 1993]. The wind-driven Labrador Sea circulation from a barotropic model was found to be enhanced in January and February and weakened in July [Greatbatch and Gouding, 1989; Greatbatch et al., 1990]. Greatbatch et al. [1990] pointed out that the annual variability of the model gyre circulation was related to the wind forcing over the entire North Atlantic. The observed winter gyre in the western Labrador Sea, first discussed by Clarke and Gascard [1983], was generated by convection after intense surface cooling [Seung, 1987]. Both hydrographic and current measurements suggest that the winter gyre is elongated in the alongshore direction with its center at $\sim 200 \mathrm{~km}$ from the shelf break. A study of surface circulation in the northwestern Labrador Sea [LeBlond et al., 1981] indicated the influences of relatively fresh and cold water from the Arctic archipelago and as runoff from the continent (also see Ikeda [1989]). However, only limited attention has been directed to the basin-scale variability in the Labrador Sea, compared with that to shelf circulation to the west [e.g., Thompson et al., 1986; Lazier and Wright, 1993]. \footnotetext{
kaido University, Sapporo, Japan.

Copyright 1996 by the American Geophysical Union.

Paper number $96 \mathrm{JC} 02778$.

0148-0227/96/96JC-02778\$09.00
}

${ }^{1}$ Now at Graduate School of Environmental Earth Sciences, Hok
Satellite altimetry such as from TOPEX/POSEIDON and Geosat is one of the newest tools that can be used to estimate the basin-scale variability in the deep ocean. Previous investigations have demonstrated the usefulness of TOPEX/ POSEIDON [e.g., Fu et al., 1994] and Geosat [e.g., Han et al., 1993] altimeter data in the study of mesoscale oceanic features. However, the altimetric signal in the Labrador Sea is relatively weak based on the previous understanding of the Labrador Sea circulation [e.g., Lazier, 1973; Clarke and Gascard, 1983]. This weaker signal presently makes altimetric analyses of the oceanic features challenging.

The principal goal of this paper is to examine basin-scale sea surface height variability from both TOPEX/POSEIDON and Geosat altimeter data in the Labrador Sea, using a mathematical technique called complex empirical orthogonal function (CEOF) analysis. We had started this analysis with Geosat data. However, it is not realistic to derive the local sea level variability in the Labrador Sea because the long-wavelength satellite orbit error in the Geosat data is still greater than or at least comparable to the basin-scale variability of interest. Instead, the along-track orbit error is removed by an empirical fit over a much longer orbit arc than the scales of interest. Such data not only contain the local sea level variability but also are influenced by that south of the Labrador Sea (see section 3.2). Hence particular attention has to be paid to this nonlocal effect in the interpretation of the Geosat results. After analyzing the Geosat data, we examined the local sea surface height variability from the first 2 years of TOPEX/POSEIDON data, which have a high measurement precision $(\sim 2 \mathrm{~cm})$ and a low orbit error $(\sim 3 \mathrm{~cm})$ [Fu et al., 1994]. The steric height anomalies from the climatological monthly-mean Levitus data [Levitus, 1982], which may represent thermal expansion/contraction, 


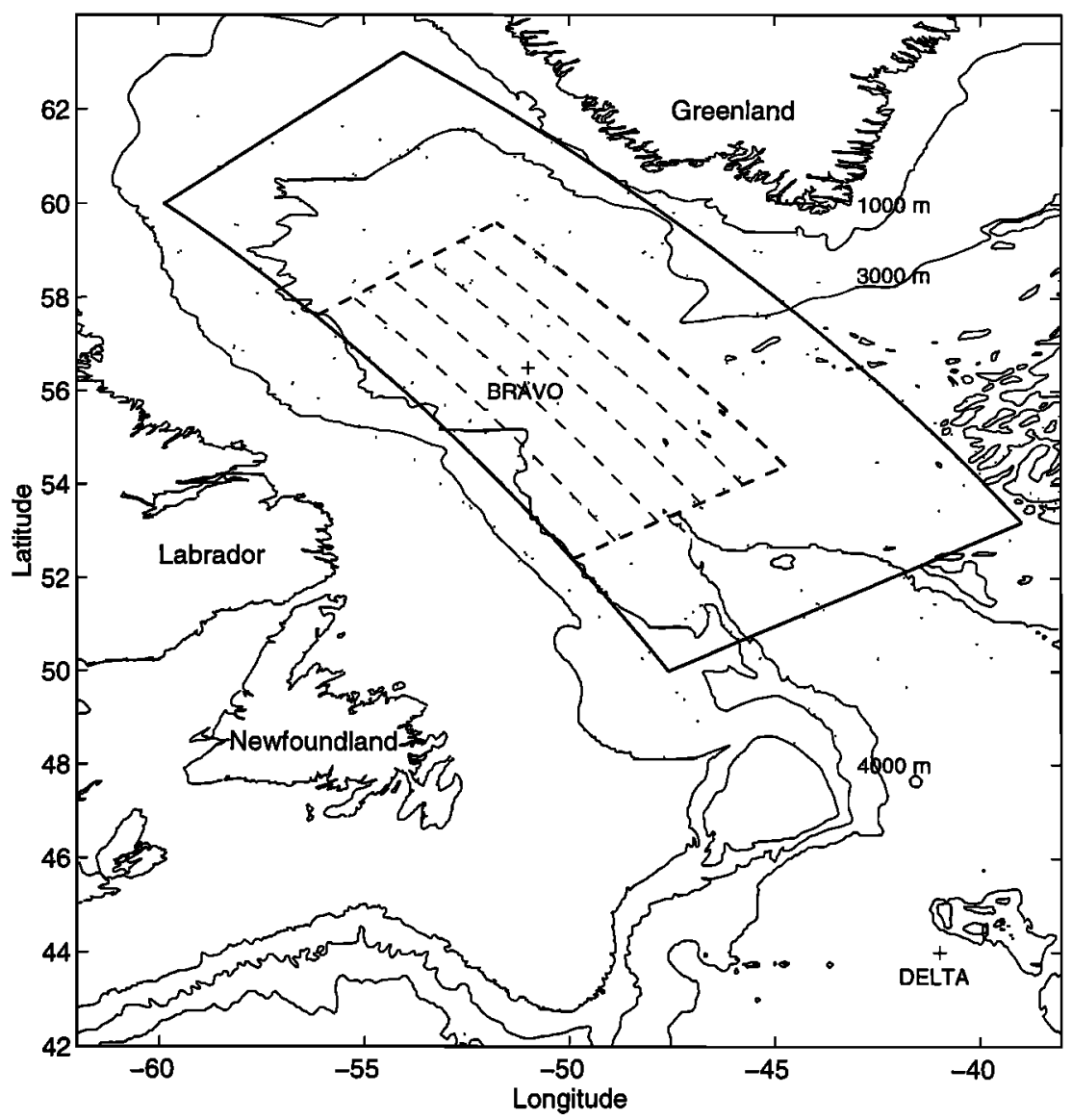

Figure 1. A map showing study regions in the Labrador Sea, along with ocean weather stations (OWS) Bravo and Delta. The thick solid lines illustrate the region where the results from the TOPEX/POSEIDON data, Levitus data, and wind-driven model results are produced. The thick dashed lines illustrate the region where the Geosat results are presented. The TOPEX/POSEIDON and Geosat ground tracks are shown as dotted and dashed lines, respectively.

freshwater input, and baroclinic wind-driven response, are analyzed to interpret the TOPEX/POSEIDON-observed basinscale variability. Likewise, a barotropic wind-driven response is examined of a linear model (A. F. Fanning and R. J. Greatbatch, personal communication, 1994). Both TOPEX/ POSEIDON and Geosat data revealed the consistent dominant features of the basin-scale sea surface height variability in the Labrador Sea, but with apparently striking discrepancies. These discrepancies are briefly explained, too.

This paper is divided into four sections. The next section describes the Geosat and TOPEX/POSEIDON altimeter dataprocessing techniques, along with the procedures of the CEOF analysis. In section 3 the analysis results of TOPEX/ POSEIDON and Geosat altimeter data are presented and interpreted using the Levitus data and barotropic wind-driven model response. Section 4 summarizes the results.

\section{Data Processing and Analysis Methods}

\subsection{Geosat Data}

The Geosat data in this study are from the Geosat Exact Repeat Mission (ERM) during the period from November 1986 to December 1988. (The data in 1989 are not used due to quality deterioration.) The Geophysical Data Records (GDR) at the ERM repeat cycles over this period have been supplied by the National Oceanic and Atmospheric Administration National Geodetic Survey [Cheney et al., 1987]. The ERM was designed to repeat ground tracks to within $1 \mathrm{~km}$ with a frequency of 17.05 days [Born et al., 1987]. Following Vazquez et al. [1990], Le Traon et al. [1990], Kelly [1991], Le Traon [1991], and Ikeda [1993], only the ascending track data are used in this study, because some of the descending track data are missing from the south of Greenland to the North Atlantic Current region and the remainder are very noisy. The unavailability of the descending track data is unfortunate but does not have a significant impact on the results in the present study since we are interested in the annual basin-scale features. Because too many data cycles are missing, the ascending track data on the eastern Labrador Sea are not considered either. As a result, only the data on six ascending tracks (see Figure 1 for their locations within the dashed line region) are used. The track separation spacing at $55^{\circ} \mathrm{N}$ is about $90 \mathrm{~km}$.

Analysis of altimetric sea surface height data begins with an application of various instrumental and environmental corrections in GDRs. They were explained in full detail by Cheney et al. [1987]. The supplied corrections for ionospheric, wet and dry tropospheric path delays, solid Earth tides, ocean tides, and an inverse barometer response of sea surface height to atmospheric pressure are all applied to each 1-s average 
height. Correction of electromagnetic bias due to sea state is also applied using $2 \%$ of significant wave height.

The corrected sea surface height data from $5^{\circ} \mathrm{N}$ to the northernmost ends of the tracks $\left(57.6^{\circ} \mathrm{N}\right.$ for the westernmost track and $59.6^{\circ} \mathrm{N}$ for the easternmost track; also see Figure 1) are interpolated and registered on a fixed latitudinal grid at $0.1^{\circ}$ intervals. A mean sea surface height is computed at each grid point from all available data, and then the mean is removed from the individual height data, producing height anomalies. Both the geoid and mean dynamic topography are removed by this process. Because only the annual variability is of interest here, the removal of the mean sea surface from Geosat height data causes no loss of signal. Orbital errors are removed by subtracting from the individual tracks a quadratic fit over the range from $5^{\circ} \mathrm{N}$ to the northernmost ends of the tracks, approximately $6000 \mathrm{~km}$. This detrending scheme has the deleterious side effect of removing long-wavelength signals in the ocean, such as basin-scale wind-driven circulation (see section 3.2). The resulting altimetric sea surface height anomalies, which still contain small-scale variability, are smoothed temporally and spatially and subsampled at $0.4^{\circ}$ latitudinal intervals using optimal linear interpolation [Bretherton et al., 1976]. The interpolation scheme is parameterized with a temporal correlation scale of 68 days and a spatial correlation scale of $150 \mathrm{~km}$. The missing data cycles (less than $8 \%$ ) are thus filled, yielding complete time series of the sea surface height anomalies. Although the temporal and spatial correlation scales are chosen somewhat arbitrarily, the temporal and spatial filtering within the interpolation does not affect our analysis of the annual basin-scale variability since the temporal correlation scale is much shorter than 1 year and the spatial correlation scale is much less than the basin scale of interest.

\subsection{TOPEX/POSEIDON Data}

The TOPEX/POSEIDON data used are from the joint TOPEX/POSEIDON mission launched on August 10, 1992, by the United States National Aeronautics and Space Administration (NASA) and the French space agency, Centre National d'Etudes Spatiales (CNES). The data are produced and distributed as merged GDRs by the Physical Oceanography Distributed Active Archive Center (PODAAC) of the NASA Jet Propulsion Laboratory. The TOPEX/POSEIDON altimetric measurements from both ascending and descending tracks within the period from December 1992 to December 1994 have been used. The satellite repeats its ground tracks every 9.9156 days. The track separation spacing at $55^{\circ} \mathrm{N}$ is about $160 \mathrm{~km}$ (see Figure 1).

Data are edited based on quality flags and parameter ranges as recommended in the user handbook [PODAAC, 1993] and corrected for various instrumental and environmental effects. The corrections supplied in the merged GDRs for wet and dry troposphere, ionosphere, electromagnetic bias, and an inverse barometric response of sea surface height to atmospheric pressure are all applied to each 1-s average height. The merged GDR ocean, Earth, and pole tides are also removed. The standard NASA Goddard Space Flight Center precise orbit based on the Joint Gravity Model-2 (JGM-2) has been used.

The corrected sea surface height data on both ascending and descending tracks from $48^{\circ} \mathrm{N}$ to about $62^{\circ} \mathrm{N}$ and $38^{\circ} \mathrm{W}$ to $60^{\circ} \mathrm{W}$ are interpolated and registered on a fixed latitudinal grid at $0.1^{\circ}$ intervals. Mean sea surface heights are computed only at grid points where more than 40 data cycles are available. (As a result, about half of the data points over the region shallower than 3000-m isobath are eliminated, mostly in the northern area.) These means are then removed from the individual height data, producing height anomalies. The resulting height anomalies on both ascending and descending TOPEX/ POSEIDON ground tracks are interpolated onto ascending Geosat ground tracks (at $0.4^{\circ}$ latitudinal intervals) within the solid-line domain (Figure 1) using optimal linear interpolation. The interpolation scheme is parameterized with a temporal correlation scale of 68 days and a spatial correlation scale of $150 \mathrm{~km}$, as in the Geosat data processing.

\subsection{Complex Empirical Orthogonal Function Analysis}

CEOF analysis (also referred to as principal component analysis) is discussed in detail by Barnett [1983] and White et al. [1987]. This technique has been applied successfully to oceanographic and meteorological data over the last decade [Barnett, 1983; White et al., 1987, 1990; Shriver et al., 1991; Matthews et al., 1992]. CEOF analysis has the ability to extract physical information about both propagating and standing dynamic features, by using the fewest possible number of propagating spatial patterns of variability to represent a space-time data set.

The first step in analyzing sea surface height anomalies is the transformation of a real data matrix into a complex data matrix, whose imaginary part is the Hilbert transform of the original data matrix. The second step is the formation of a covariance matrix for the new complex data matrix. The last step is the eigenmode decomposition of the covariance matrix. The low-order eigenmodes of the covariance matrix contain amplitude and phase information describing the principal components of the original data series.

For each eigenmode, there are four empirical measures that characterize features in CEOFs, consisting of the spatial distribution of amplitude and phase of the empirically derived orthogonal function and the corresponding time series. The spatial distribution of amplitude reveals the locations of local maxima and minima of the function, whereas the distribution of phase reveals the propagation direction. Also, the spatial gradient of phase is the local wavenumber. The time series of amplitude indicates when the stronger/weaker spatial amplitude pattern occurs. The time series of phase indicates instantaneous frequencies of observed variability, and the dominant period is determined by the time required for the phase to change $360^{\circ}$. The combination of the above four measures gives a complete pattern of the eigenmode.

\section{Results}

CEOF analysis is carried out to extract spatial and temporal patterns of the altimetric sea surface height anomalies in the Labrador Sea. Only the first eigenmode will be presented and discussed, since this eigenmode dominates the variance of the sea surface height anomalies. Note that in the CEOF analysis, we arbitrarily choose a phase origin for the spatial phase pattern at the northeast corners of the study domains. The phase values in both the spatial and temporal phase patterns depend on this choice. But the phase for the height anomalies is the difference between the temporal and spatial phases and is independent of the choice. Hereafter the spatial pattern of amplitude is shown with a unit of centimeters, while its time series is dimensionless with a mean value of 1 .

\subsection{TOPEX/POSEIDON}

The spatial and temporal patterns of the first CEOF eigenmode are presented in Figure 2. The first CEOF eigenmode 
a)

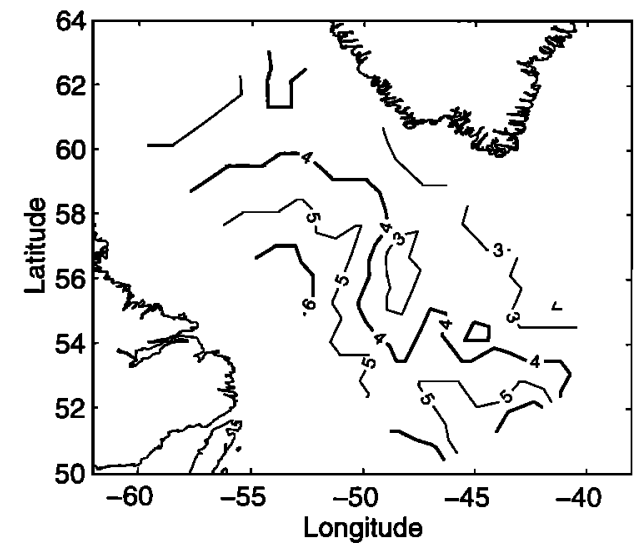

c)

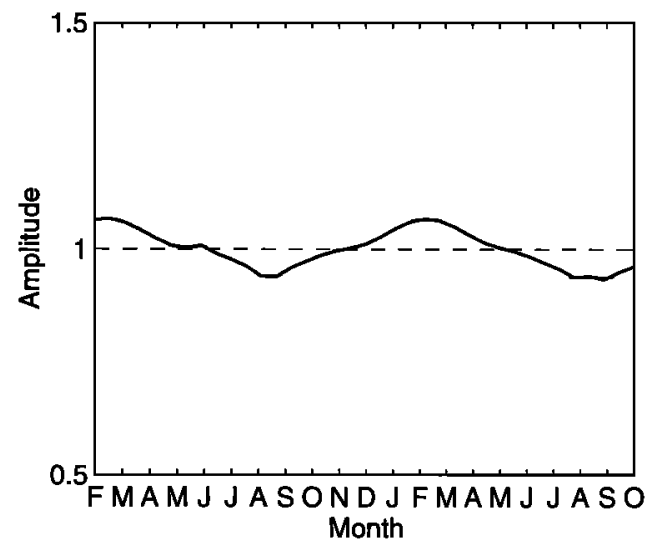

b)

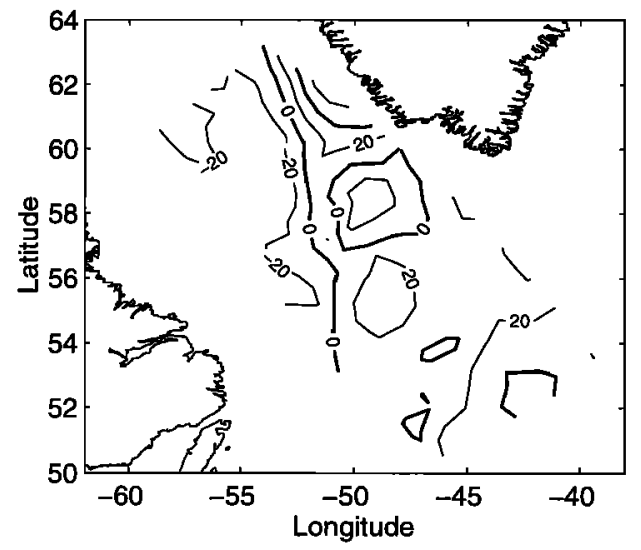

d)

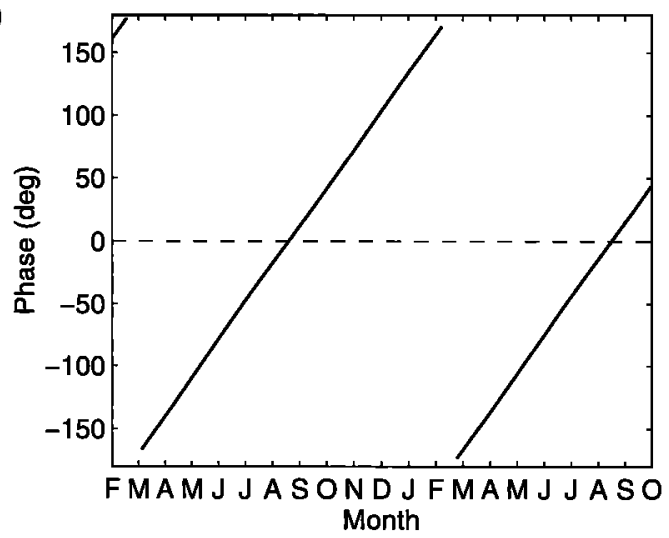

Figure 2. First-eigenmode functions of CEOF analysis for TOPEX/POSEIDON sea surface height anomalies in the Labrador Sea over the period from December 1992 to November 1994. They are spatial patterns of (a) amplitude and (b) phase and temporal patterns of (c) amplitude and (d) phase. The percentage of total variance explained by the first eigenmode is $85 \%$. The contour intervals are $1 \mathrm{~cm}$ for amplitude and $20^{\circ}$ for phase. The temporal amplitude is dimensionless.

accounts for $85 \%$ of the variance of the sea surface height anomalies. The spatial pattern of amplitude (Figure $2 a$, in centimeters) shows some variations, stronger in the western Labrador Sea and weaker in the eastern Labrador Sea, superimposed upon a uniform pattern. The maximum variability coincides with the place where the winter gyre in the western Labrador Sea was found by Clarke and Gascard [1983]. The increasing strength near the southern edge may represent the North Atlantic Current characterized by much stronger variability. The phase of the spatial pattern (Figure 2b) is nearly uniform in the southern and central Labrador Sea. However, there is significant phase change in the northern area. We are not sure if this phase change represents nearby boundary currents (Labrador Current to the west, Western Greenland Current to the east, which turns westward in Davis Strait) whose annual cycle may have different timing or is an artifact due to the data sparsity. In the temporal variability the amplitude (Figure 2c, dimensionless) in winter is slightly larger than in summer, while the phase (Figure $2 \mathrm{~d}$ ) progresses almost linearly with time at a 1-year period, indicating a dominant annual variation.

The sea surface height anomalies can be obtained from a cosine function, whose amplitude is a product of the spatial amplitude (Figure 2a) and the time series (Figure 2c) and whose phase is a difference between the spatial phase (Figure 2b) and the time series (Figure 2d). Therefore the height anomalies of the first eigenmode have an annual variation with amplitudes of $\sim 6(\sim 4) \mathrm{cm}$ in the western (eastern) Labrador Sea. Positive anomalies occur in summer/fall and the negative ones in winter/spring.

The sea surface height anomalies described above may be interpreted as a composite of steric effect and wind setup. The steric height relative to $500 \mathrm{~dB}$ is estimated from the $1^{\circ}$ by $1^{\circ}$ climatological monthly-mean Levitus data set for the region between $40^{\circ} \mathrm{N}$ and $64^{\circ} \mathrm{N}$ and $64^{\circ} \mathrm{W}$ and $40^{\circ} \mathrm{W}$. A complete description of the Levitus data set was given by Levitus [1982]. Bilinear interpolation is used to deduce the steric height within the TOPEX/POSEIDON grid domain in the Labrador Sea. At each grid point a mean is calculated and subsequently removed from each individual height. The resulting monthly-mean steric height anomalies have been extended to the same duration as the TOPEX/POSEIDON data cover. The CEOF analysis is carried out following the procedures used for the altimeter data.

The first eigenmode accounts for $99 \%$ of the variance of the steric height anomalies of the Levitus data. The spatial and temporal patterns of the first eigenmode are shown in Figure 3. The spatial pattern of amplitude (Figure 3a, in centimeters) shows little variations, except in the northern Labrador Sea where variability increases northward from $57^{\circ} \mathrm{N}$. The phase of 
a)

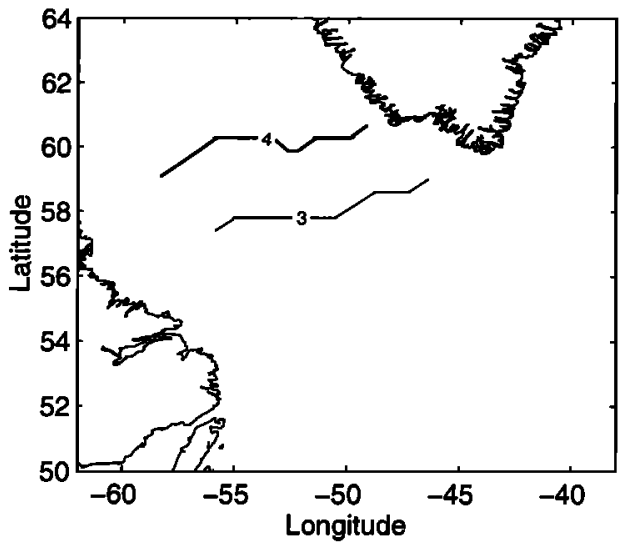

c)

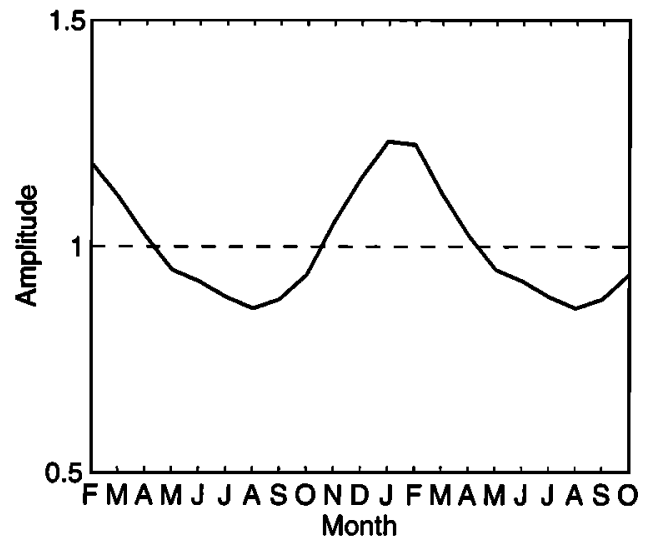

b)

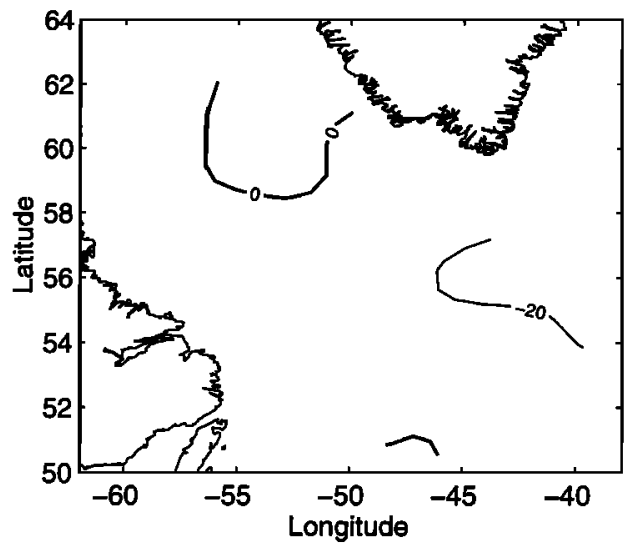

d)

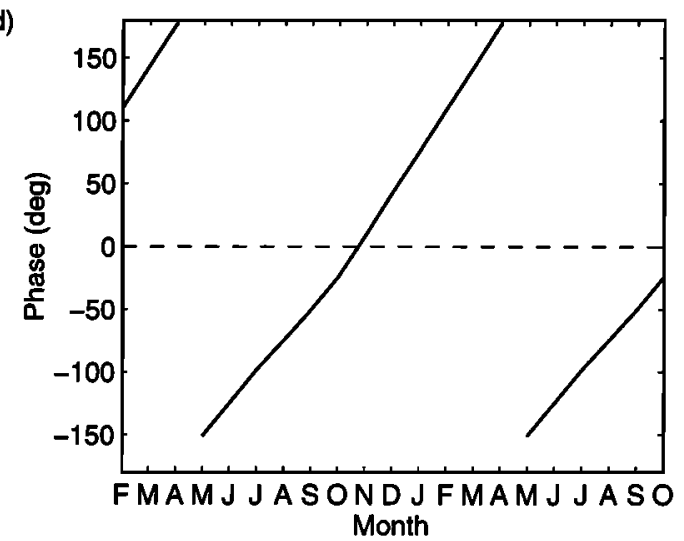

Figure 3. Same as Figure 2 but for the steric height anomalies estimated from the climatological monthlymean Levitus data. The first eigenmode accounts for $99 \%$ of the total variance.

the spatial pattern (Figure $3 \mathrm{~b}$ ) is nearly uniform, with a shift of less than 1 month. In the temporal variability the amplitude (Figure 3c, dimensionless) has a substantial annual oscillation, stronger in winter and weaker in summer, superimposed upon a constant pattern. The phase (Figure 3d) progresses almost constantly with time at a 1-year period, suggesting that an annual cycle dominates. Altogether, this first eigenmode has an annual cycle with an amplitude of $\sim 3 \mathrm{~cm}$, positive in summer and negative in winter. The Levitus results are also supported by observations at ocean weather station (OWS) Bravo. Using the monthly average temperature and salinity over the top 500 $\mathrm{dB}$ at OWS Bravo $\left(56^{\circ} 30^{\prime} \mathrm{N}, 51^{\circ} 00^{\prime} \mathrm{W}\right)$ in the central Labrador Sea [Shuhy, 1978], we obtain a steric height difference of $5 \mathrm{~cm}$ between summer and winter, i.e., an annual cycle with an amplitude of $2.5 \mathrm{~cm}$.

We have calculated zero-lag correlation coefficients (left panel, Figure 4a) between the first-eigenmode TOPEX/ POSEIDON and Levitus results and ratios (right panel, Figure 4a) of their root-mean-square (RMS) differences to RMS values of the TOPEX/POSEIDON results. The correlation coefficients generally decrease northwestward, with the difference ratios increasing. The correlation coefficients in the southern and central Labrador Sea are larger than 0.5 , while the difference ratios are less than 0.6 , suggesting that the steric effect is a major contributor to the observed basin-scale variability in the study region. In contrast, the correlation coefficients are lower than 0.5 and the difference ratios are close to 1 in the northwestern corner. Here significant influences of fresher and colder water are expected [LeBlond et al., 1981; Ikeda, 1989], which may have smaller scales than and different timing from the annual cycle of thermal expansion. However, the low correlation and high difference ratio may be resulted from the TOPEX/POSEIDON data sparsity in this area. A close examination suggests that the steric height field in the central and southern Labrador Sea (Figure 3), at the lowest order, is uniform and can approximately account for the spatially uniform portion of the TOPEX/POSEIDON results (Figure 2). On the top of this the larger amplitude in the western part (Figure 2a) may be attributed to more intense wintertime cooling [Clarke and Gascard, 1983; Seung, 1987]. This smaller-scale feature, however, may have been averaged out in the Levitus data, since they are climatological monthly and one-degree-square means and subject to further smoothing using objective analysis [Levitus, 1982].

The wind setup is now discussed based upon a wind-driven numerical model. The sea surface height signals produced by a $1^{\circ}$ by $1^{\circ}$ resolution model of the North Atlantic between $10^{\circ} \mathrm{S}$ and $65^{\circ} \mathrm{N}$ are analyzed using the CEOF analysis, similar to that for the TOPEX/POSEIDON altimetric data. A complete description of the model has been given by Greatbatch et al. [1990]. The model is barotropic and has linear bottom friction. It is forced by monthly-mean wind stress anomalies (A. F. Fanning and R. J. Greatbatch, personal communication, 1994). Bilinear interpolation is used to deduce model-calculated sea surface height anomalies within the TOPEX/POSEIDON data domain of the Labrador Sea. The CEOF analysis is carried out 


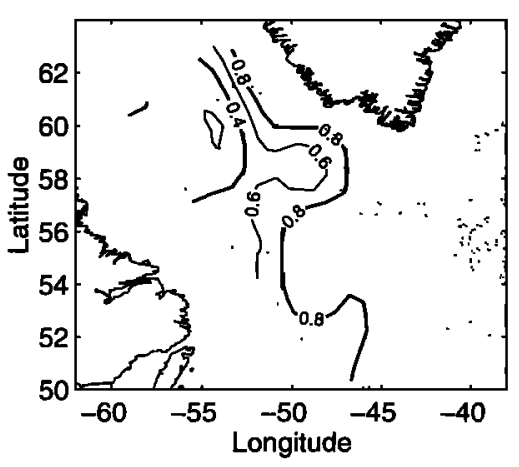

a)
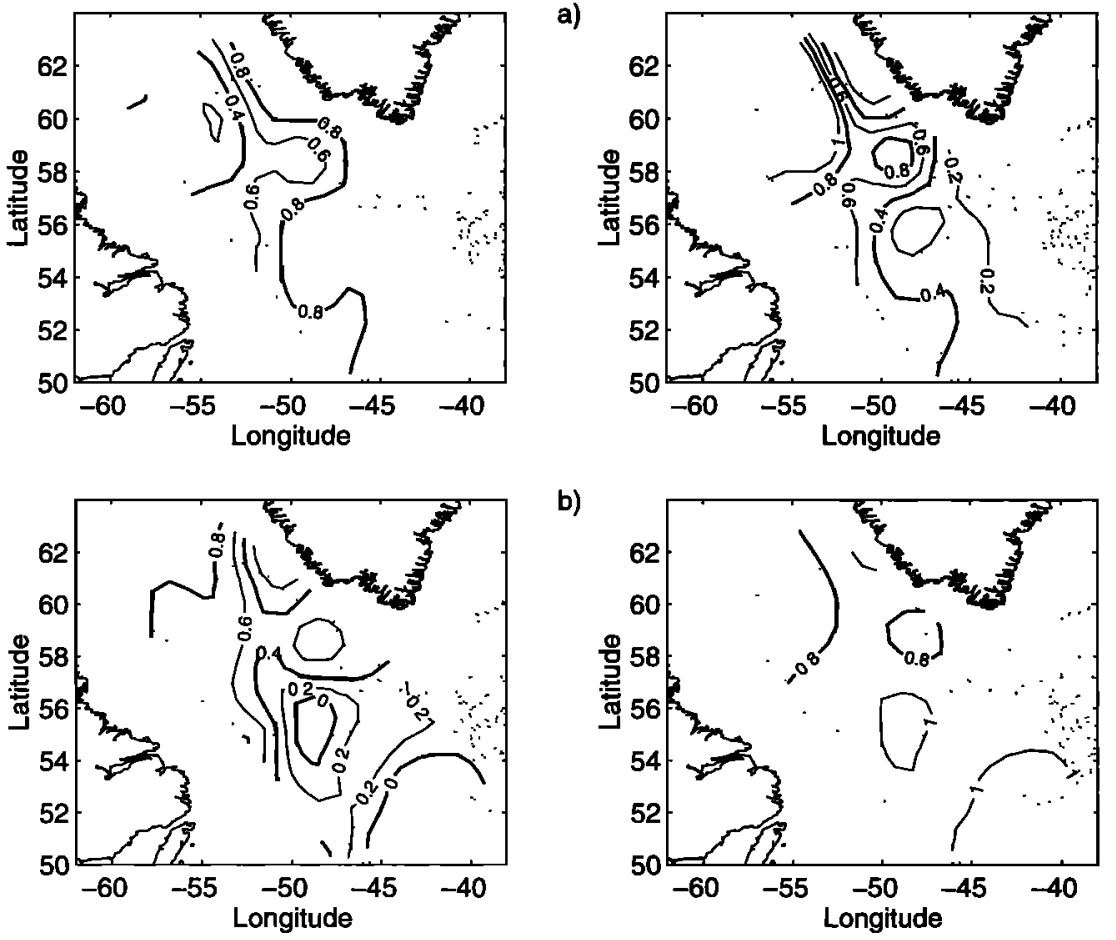

b)
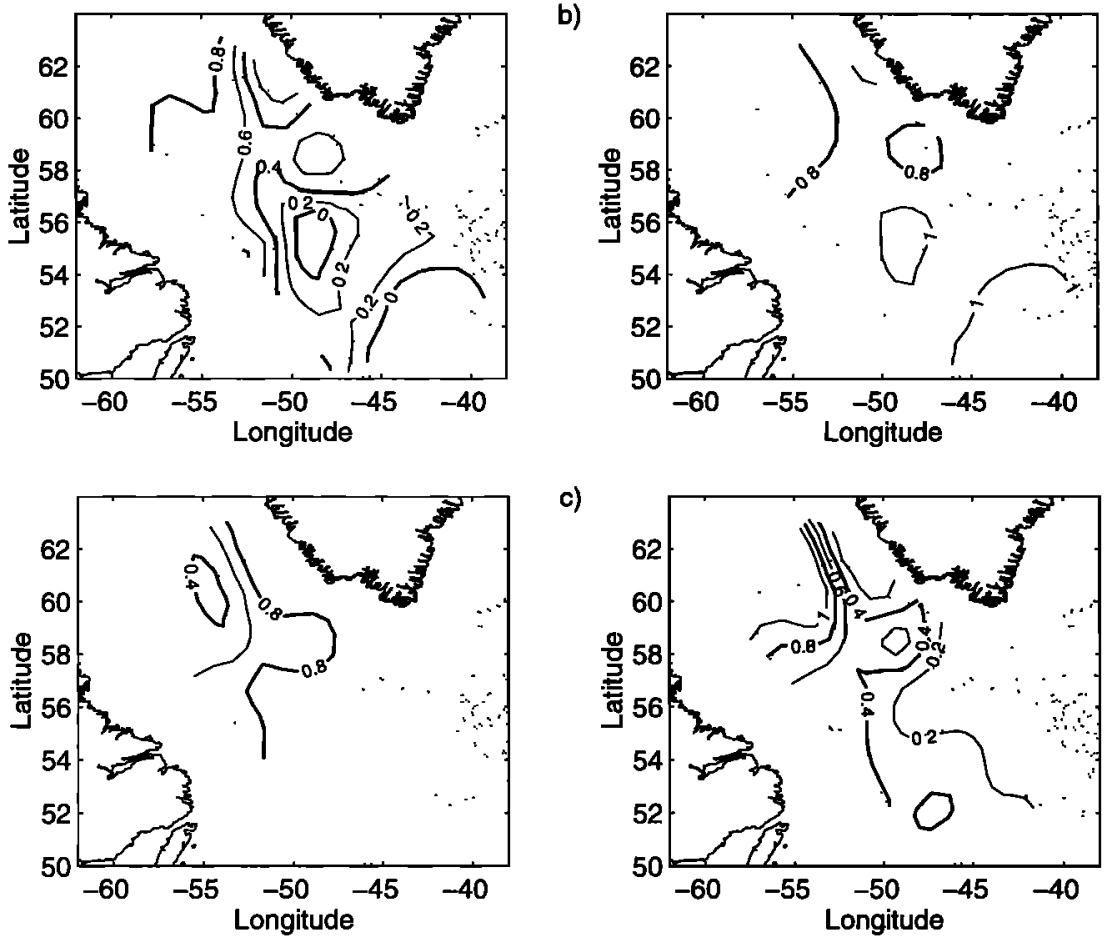

c)

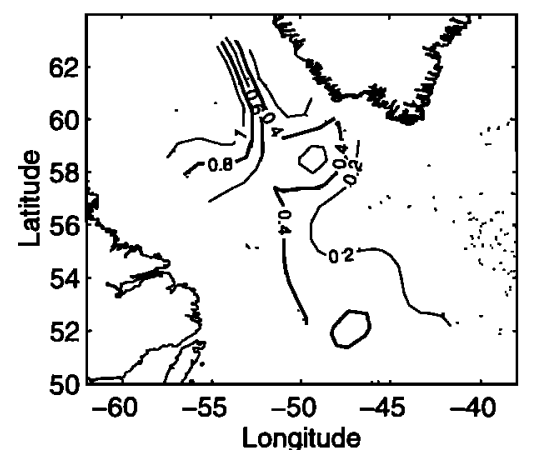

Figure 4. (left) Correlation coefficients and (right) ratios of the root-mean-square differences between the first-eigenmode TOPEX/POSEIDON results and (a) thermal expansion from the Levitus data, (b) winddriven response from a barotropic model, and (c) sum of the thermal expansion and wind-driven response. The $3000-\mathrm{m}$ isobath is also shown by the dotted line.

on the model results following the procedures used for the altimetric data. The first eigenmode accounts for $76 \%$ of the variance of the sea surface height anomalies produced by the model. The spatial and temporal patterns of the first eigenmode are shown in Figure 5. The spatial pattern of amplitude (Figure 5a, in centimeters) shows some variations, stronger in the northwestern Labrador Sea and weaker in the southeastern Labrador Sea. The phase of the spatial pattern (Figure 5b) is nearly uniform. In the temporal variability the amplitude (Figure $5 c$, dimensionless) exhibits an annual oscillation stronger in winter and weaker in summer, superimposed upon a constant pattern. The phase (Figure 5d) progresses almost constantly with time at a 1-year period, indicating a dominant annual variability. Altogether, this first eigenmode has an annual cycle with an amplitude less than $1 \mathrm{~cm}$, positive in summer and negative in winter.

The zero-lag correlation coefficients (left panel, Figure 4b) and RMS difference ratios (right panel, Figure $4 b$ ) between the first-eigenmode TOPEX/POSEIDON and wind-driven model results are also calculated. Compared to the steric effect, the wind-driven sea surface height variability shows generally lower correlation with the TOPEX/POSEIDON observations. The high correlation occurs only near the central Labrador Sea, but the difference ratios are larger than 0.8 all over the domain, indicating that the wind-driven portion in the TOPEX/POSEIDON observations is at best minor relative to the steric effect. This is further verified by examining the correlation coefficients (left panel, Figure 4c) and the difference ratios (right panel, Figure 4c) between the TOPEX/POSEIDON data and the Levitus data plus wind-driven model results. The addition of the wind-driven model response to the steric effect leads to an overall but slight increase of the correlation coefficients and a similar decrease of the difference ratios. Hence the improvement is marginal.

In summary, the steric effect (dominated by thermal expansion) in the Levitus data, supplemented by the barotropic wind-driven setup, can account for the majority of the basinscale sea level variability in the Labrador Sea deduced from 
a)

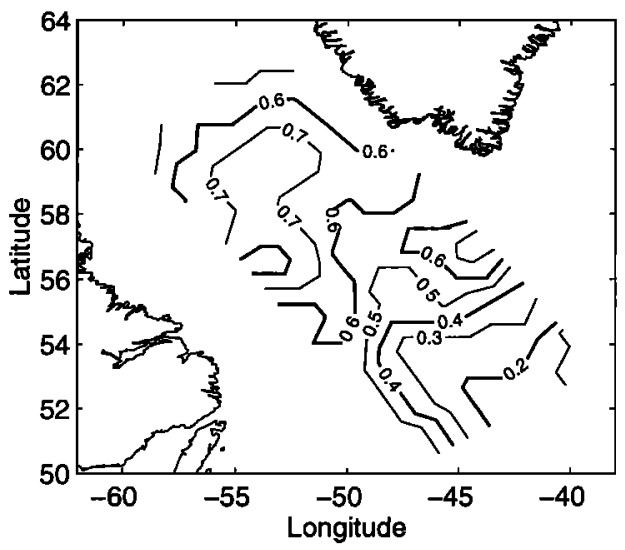

c)

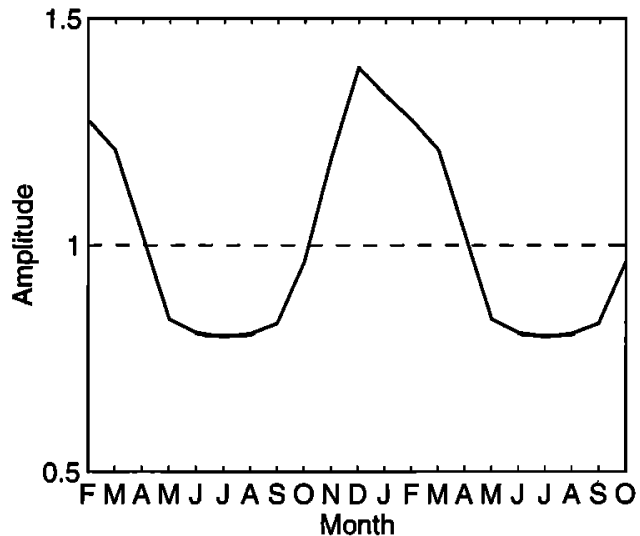

b)

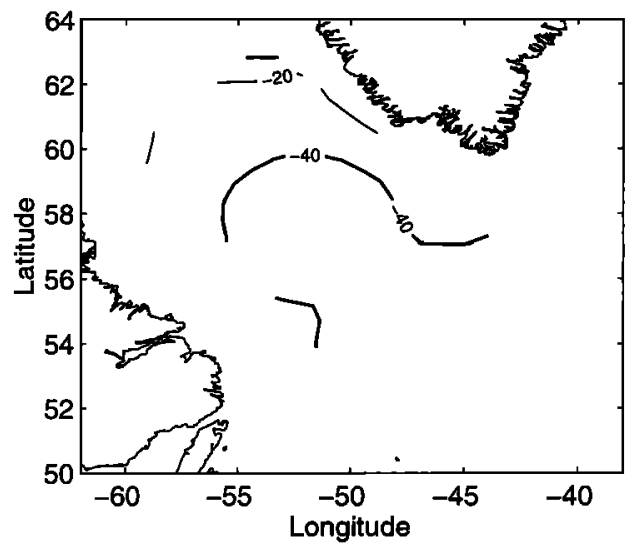

d)

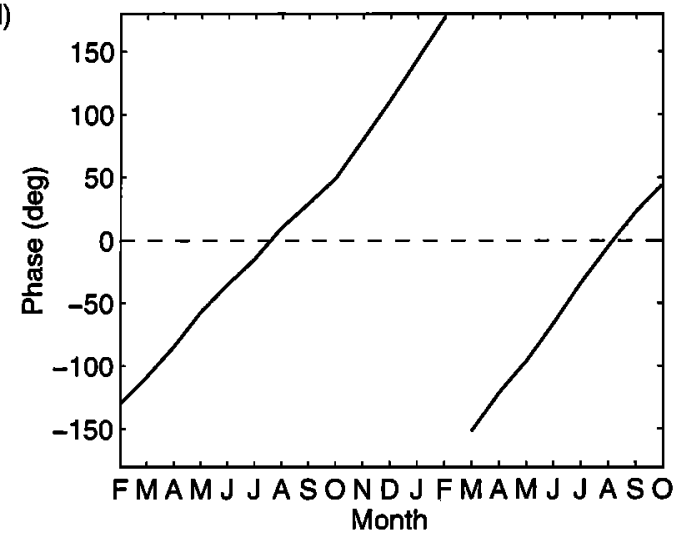

Figure 5. Same as Figure 2 but for the monthly-mean sea surface height anomalies from a wind-driven barotropic model. The first eigenmode accounts for $76 \%$ of the total variance. The modeled data are produced with a $1^{\circ}$ by $1^{\circ}$ resolution numerical model of the North Atlantic between $10^{\circ} \mathrm{S}$ and $65^{\circ} \mathrm{N}$. The contour intervals are $0.1 \mathrm{~cm}$ for amplitude and $20^{\circ}$ for phase. The temporal amplitude is dimensionless.

TOPEX/POSEIDON altimeter data. The sea surface height anomalies in the TOPEX/POSEIDON data have an annual amplitude of $\sim 5 \mathrm{~cm}$, with positive anomalies in summer and negative ones in winter. We have also noticed that the temporal amplitude is stronger in winter than in summer (see Figures $2 c, 3 c$, and $5 c$ ) from the TOPEX/POSEIDON, Levitus, and wind-driven results; that is, the amplitude of the negative anomaly in winter is larger than that of the positive anomaly in summer. The larger amplitude in winter may be attributed to two factors. One is the warming and cooling phase shift from the sea surface to deeper layers during the period from spring to fall [see Shuhy, 1978], which makes the steric height have a reduced but broader distribution in summer than in winter. The other is the larger amplitude of the southeastward wind stress anomaly in winter than that of the northwestward wind stress anomaly in summer [see Greatbatch et al., 1990].

\subsection{Geosat}

The spatial and temporal patterns of the first CEOF eigenmode from Geosat data are presented in Figure 6. The first CEOF eigenmode accounts for $65 \%$ of the variance of the sea surface height anomalies. The spatial pattern of amplitude (Figure 6a, in centimeters) shows relatively strong signal at high latitudes and toward the western and eastern boundaries. The temporal pattern of amplitude (Figure 6c) has no explicit indication of wintertime intensification. The phase of the spa- tial pattern (Figure 6b) increases from north to south on the western side, with a phase difference of about 60 degrees. In contrast, the phase decreases to the south on the eastern side, with a phase difference of $\sim 120$ degrees. The temporal pattern of phase (Figure 6d), which is dimensionless, varies nearly constantly with time and indicates dominant annual variability. The combination of these four patterns in Figure 6 has revealed that the first eigenmode has an annual variation with a $\sim 2$-cm amplitude increasing toward the Labrador coast on the western side and toward the Greenland coast on the eastern side. Positive anomalies occur in winter/spring and the negative ones in summer/fall.

Compared with the TOPEX/POSEIDON results in Figure 2, we can find striking basin-wide and local discrepancies in Figure 6. Although the latter are expected, the basin-wide reversal of the sea surface height anomalies is surprising at the first look. Why do the Geosat results (Figure 6) show opposite anomalies to the TOPEX/POSEIDON observations (Figure 2)? Here we give an interpretation of the Geosat results with reference to the TOPEX/POSEIDON ones. At OWS Bravo we have shown the annual amplitude of $\sim 2.5 \mathrm{~cm}$ for the steric height anomalies. In contrast, the steric height anomalies over the top $500 \mathrm{~dB}$ at OWS Delta $\left(44^{\circ} 00^{\prime} \mathrm{N}, 41^{\circ} 00^{\prime} \mathrm{W}\right)$ [Jones, 1979] south of the North Atlantic Current are estimated to have an annual amplitude of $\sim 8 \mathrm{~cm}$, based on the OWS observations. 
a)

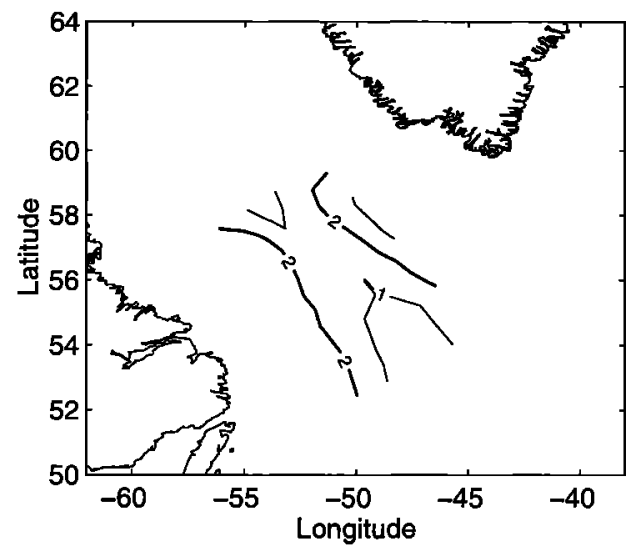

c)

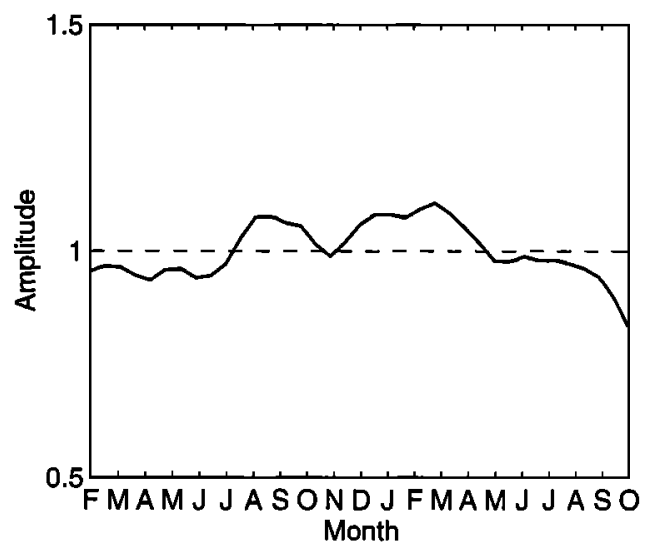

b)

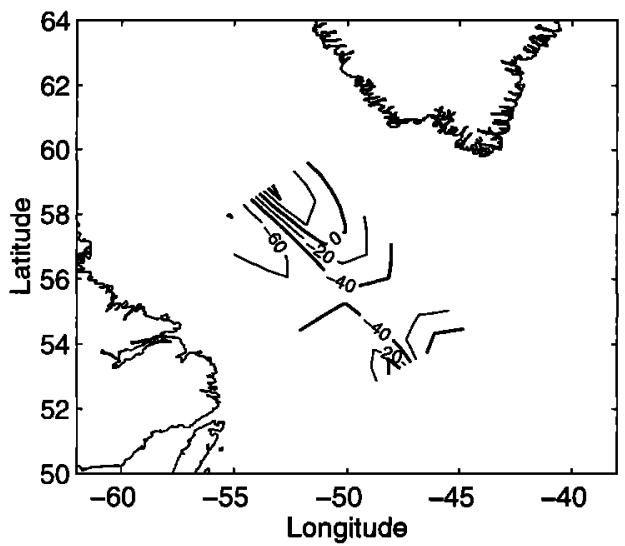

d)

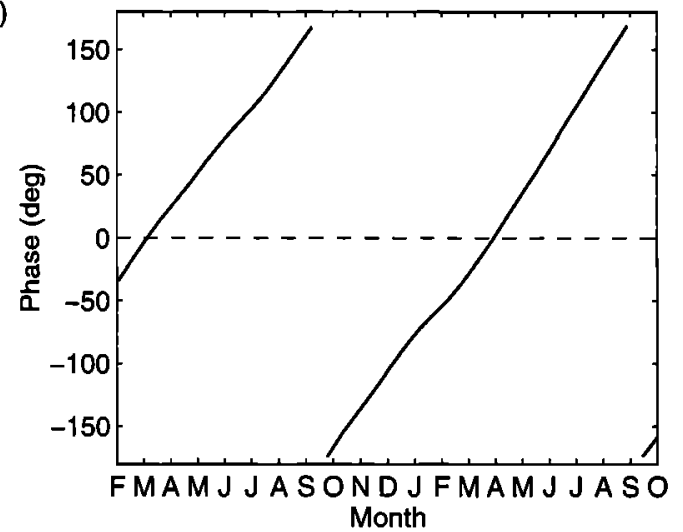

Figure 6. First-eigenmode functions of CEOF analysis for Geosat sea surface height anomalies in the Labrador Sea over the period from November 1986 to December 1988. They are spatial patterns of (a) amplitude and (b) phase and temporal patterns of (c) amplitude and (d) phase. The percentage of total variance explained by the first eigenmode is $65 \%$. The contour intervals are $1 \mathrm{~cm}$ for amplitude and $20^{\circ}$ for phase. The temporal amplitude is dimensionless.

The contribution of the layers below this top layer is negligible to the sea surface height anomalies. At both stations the steric height anomalies are positive in summer and negative in winter, being dominated by an annual variation in temperature. The north-south structure of the steric heights has a sharp gradient across the North Atlantic Current.

The wintertime steric height anomalies along the western- most Geosat ground track from $5^{\circ} \mathrm{N}$ to $58^{\circ} \mathrm{N}$, estimated over the top $500 \mathrm{~dB}$ from the Levitus [1982] data, are presented in Figure 7a (solid line). The steric height anomalies from the Levitus data are consistent with those from the OWS observations. An along-track quadratic fit from $5^{\circ} \mathrm{N}$ to $58^{\circ} \mathrm{N}$ (dashed line in Figure 7a) is estimated and subsequently removed from the steric height anomalies, as done for the Geosat altimeter
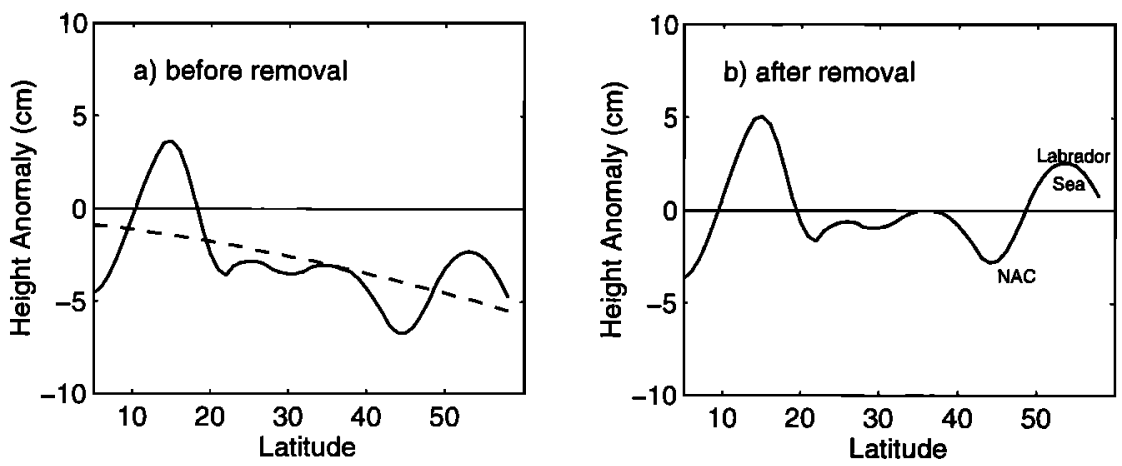

Figure 7. Diagram illustrating the wintertime steric height anomalies over the top $500 \mathrm{~dB}$ along a Geosat ground track (a) before and (b) after the quadratic-fit removal. The dashed line in Figure 7a represents the quadratic fit to the original data. It is obvious that the quadratic-fit removal results in the reversal of the steric height anomalies in the Labrador Sea. NAC is North Atlantic Current. 
height data. It can be seen that the resulting height anomalies (Figure 7b) in the Labrador Sea become positive in winter, with a magnitude of $\sim 3 \mathrm{~cm}$. Likewise, the summertime height anomalies (not shown) after the quadratic-fit removal become negative in this region. It is obvious that the quadratic-fit removal is responsible for the reversal of the anomalies in the Labrador Sea. We can infer therefore that the along-track quadratic-fit removal for the orbit error correction results in the reversal of the Geosat-observed sea surface height anomalies in the Labrador Sea. It is thus suggested that the Geosatobserved height anomalies at the lowest order represent the steric height anomalies in the Labrador Sea. However, this representation, influenced by the sea surface height variability south of the Labrador Sea, is implicit.

Now we examine what role the wind-driven sea surface height variability plays in the Geosat results (Figure 5). In order to answer this question, we analyzed the detrended winddriven model results using CEOF analysis, wherein the alongtrack quadratic fit from $5^{\circ} \mathrm{N}$ to about $58^{\circ} \mathrm{N}$ is estimated and subsequently removed from the model output, as done for the Geosat height,data. The first eigenmode accounts for $74 \%$ of the variance of the detrended sea surface height anomalies. Only the spatial amplitude pattern of the first eigenmode (Figure 8) is shown. The first eigenmode (Figure 8) is extremely weak and negligible compared with original model results (Figure 6a). Since an external deformation radius is large (over $1000 \mathrm{~km}$ ); the barotropic wind-driven model responds only to large-scale wind stress patterns. As a result the basin-scale sea surface height variability from this barotropic model is significantly reduced by the removal of the along-track quadratic fit. We can infer therefore that the wind-driven basin-scale response in the Labrador Sea shows no signal in the Geosat results due to the along-track orbit error removal.

As discussed above, we have shown that the Geosat results contain the steric effect (relative to the variability of the North Atlantic Current and subtropical gyre circulation) only, while the barotropic wind-driven portion has been removed along with the long-wavelength orbit error. Although they agree at the lowest order for the basin-scale thermal expansion patterns, some detailed discrepancies have been observed betweén TOPEX/POSEIDON and Geosat data. These discrepancies could possibly be induced by interannual variability (1986-1988 for the Geosat data and 1992,1994 for the TOPEX/POSEIDON data), data quality differences (discussed in section 4), and processing techniques (e.g., the along-track detrending for the Geosat data).

\section{Discussion and Summary}

The CEOF analyses of the 2-year TOPEX/POSEIDON and 2-year Geosat altimeter data in this study have improved our understanding of the annual variation of the Labrador Sea circulation. The results herein support the conventional wisdom regarding the basin-scale variability of the sea surface height anomalies in the Labrador Sea and provide additional insight through the intercomparison among satellite altimetry, the Levitus data, and a wind-driven barotropic model. These results show that the sea surface height anomaly from the TOPEX/POSEIDON data has an annual amplitude of $\sim 5 \mathrm{~cm}$, with a positive anomaly in summer/fall and a negative one in winter/spring. The annual cycle in the Levitus data, dominated by thermal expansion, has an amplitude of $\sim 4 \mathrm{~cm}$ and is nearly in phase with the TOPEX/POSEIDON data. The wind-driven

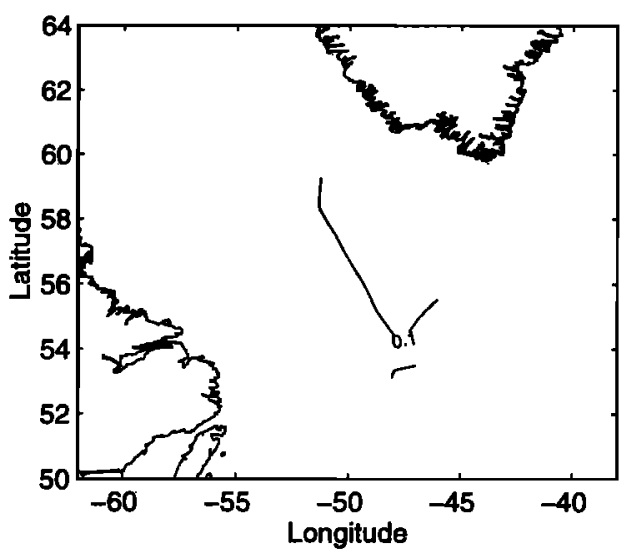

Figure 8. Same as Figure 6a but for the model-calculated sea surface height anomalies with the along-track quadratic fit removed. The first eigenmode accounts for $74 \%$ of the total variance. The contour interval is $0.1 \mathrm{~cm}$ for amplitude.

annual signal is approximately in phase with the TOPEX/ POSEIDON and Levitus data, but its amplitude is less than $\sim 1$ $\mathrm{cm}$. The correlation analysis thus suggests that the annual cycle of thermal expansion can explain the majority of that in the TOPEX/POSEIDON data, while the wind-driven contribution is minor: The present study has also shown that the longwavelength orbit error correction (i.e., the along-track detrending) obscures the annual basin-scale variability in the Geosat data. It is found that the annual cycle in the Geosat data is modified by the orbit error removal so much that the phase changes by $180^{\circ}$ and the wind-driven portion is removed.

For the annual basin-scale variability, major deficiencies in the Geosat data include the long-wavelength orbit and ocean tide errors. The required along-track orbit error correction removes the large-scale wind-driven circulation in the Labrador Sea. The resulting Geosat results become the sea surface height anomalies relative to those of the subtropical gyre circulation and of the North Atlantic Current and therefore have been obscured. This explains not only the reversal of the Geosat-observed height anomalies in the Labrador Sea but also detailed discrepancies in the spatial patterns between the TOPEX/POSEIDON and Geosat results. The dominant $\mathrm{M}_{2}$ tide is aliased by the Geosat sub-Nyquist sampling to have an apparent period of 317 days, and so the $\mathrm{M}_{2}$ tidal error may contaminate the annual cycle. In addition, the detailed discrepancies between the TOPEX/POSEIDON and Geosat results may be attributed to different accuracies in the altimetric measurements and various environmental corrections such as for ionospheric and wet tropospheric effects.

TOPEX/POSEIDON altimeter data, with an accuracy of $\sim 5$ cm (RMS) for a single-pass sea level measurement [Fu et al., 1994], are much superior to Geosat data in terms of data quality. The accuracy for the temporally varying component of the TOPEX/POSEIDON measurement is certainly better than $5 \mathrm{~cm}$ since the time-invariant systematic error component is removed (e.g., Morris and Gill [1994] found an overall RMS difference of $3 \mathrm{~cm}$ between the TOPEX/POSEIDON and simultaneous tide-gauge measurements around the Great Lakes). The aliased periods of major tidal constituents (e.g., about 2 months for the $M_{2}$ constituent) are far away from the annual cycle so that the tidal errors can be separated from the annual cycle of interest. Therefore the TOPEX/POSEIDON- 
observed basin-scale signals of $\sim 5 \mathrm{~cm}$ in the Labrador Sea are above marginal. Finally, the general consistency and high correlation between the basin-scale altimetric results and the sum of the Levitus hydrographic data and wind-driven model response demonstrate that the signals are of oceanographic origin. Sensitivity studies also indicate that the annual basin-scale variability in the Labrador Sea as deduced from TOPEX/ POSEIDON data is insensitive to all the environmental and tidal corrections (see section 2.2), suggesting the robustness of the results.

Acknowledgments. We are particularly grateful to A. F. Fanning and R. J. Greatbatch for providing the model-calculated sea surface heights and R. Hendry for providing his software for calculating geopotential anomalies from the Levitus data set. We also wish to thank R. Hendry and D. Wright for reading an early version of this manuscript. Many helpful comments by two JGR reviewers are greatly appreciated. The TOPEX/POSEIDON data were obtained from the NASA PODAAC at the Jet Propulsion Laboratory, California Institute of Technology. The work in this paper was supported by the Federal Panel on Energy Research and Development, the Department of Fisheries and Oceans, and the Natural Science and Engineering Research Council of Canada.

\section{References}

Barnett, T. P., Interaction of the Monsoon and Pacific trade wind system at interannual time scales, I, The equatorial zone, Mon. Weather Rev., 111, 756-773, 1983.

Born, G. H., J. L. Mitchell, and G. A. Heyler, Design of the Geosat Exact Repeat Mission, Johns Hopkins APL Tech. Dig., 8, 260-266, 1987.

Bretherton, F. P., R. E. Davis, and C. B. Fandry, A technique for objective analysis and design of oceanographic experiments applied to MODE-73, Deep Sea Res., 23, 559-582, 1976.

Cheney, R. E., B. C. Douglas, R. W. Agreen, L. Miller, D. L. Porter and N. S. Doyle, Geosat altimeter geophysical data record-User handbook, NOAA Tech. Memor. NOS-NGS-46, Natl. Oceanic and Atmos. Admin., Silver Spring, Md., 1987.

Clarke, R. A., and J. C. Gascard, The formation of Labrador Sea water, I, Large-scale processes, J. Phys. Oceanogr., 13, 1764-1778, 1983.

Fu, L. L., E. J. Christensen, C. A. Yamarone Jr., M. Lefebvre, Y. Menard, M. Dorrer, and P. Escudier, TOPEX/POSEIDON mission overview, J. Geophys. Res., 99(C12), 24,369-24,381, 1994.

Greatbatch, R. J., and A. Goulding, Seasonal variations in a linear barotropic model of the North Atlantic driven by the Hellerman and Rosenstein wind stress field, J. Phys. Oceanogr., 19, 572-595, 1989.

Greatbatch, R. J., B. de Young, A. Goulding, and J. Craig, On the influence of local and North Atlantic wind forcing on the seasonal variation of sea level on the Newfoundland and Labrador Shelf, $J$. Geophys. Res., 95(C4), 5279-5289, 1990.

Han, G., M. Ikeda, and P. C. Smith, Annual variation of sea-surface slopes over the Scotian Shelf and Grand Banks from Geosat altimetry, Atmos. Ocean, 31(4), 591-615, 1993.

Ikeda, M., A review of sea ice and ocean modeling relevant to the Labrador and Newfoundland Shelves, IEEE Trans. Geosci. Remote Sens., 27(5), 535-540, 1989.

Ikeda, M., Mesoscale variabilities and Gulf Stream bifurcation in the
Newfoundland Basin observed by the Geosat altimeter data, Atmos. Ocean, 3l(4), 567-589, 1993.

Jones, D. T., Oceanographic observations at North Atlantic ocean station Delta-Terminal report 1966-1973, Oceanogr. Rep. 373-80, U.S. Coast Guard, Washington, D. C., 1979.

Kelly, K. A., The meandering Gulf Stream as seen by the Geosat altimeter: Surface transport, position, and velocity variance from $73^{\circ}$ to $46^{\circ} \mathrm{W}, \mathrm{J}$. Geophys. Res., 96(C9), 16,721-16,738, 1991.

Lazier, J. R. N., The renewal of Labrador Sea water, Deep Sea Res., 20 , 341-353, 1973.

Lazier, J. R. N., and D. G. Wright, Annual velocity variations in the Labrador Current, J. Phys. Oceanogr., 23, 659-678, 1993.

LeBlond, P. H., T. R. Osborn, D. O. Hodgins, R. Goodman, and M. Metge, Surface circulation in the western Labrador Sea, Deep Sea Res., Part A, 28, 683-693, 1981.

Le Traon, P. Y., Time scales of mesoscale variability and their relationship with space scales in the North Atlantic, J. Mar. Res., 49, 467-492, 1991.

Le Traon, P. Y., M. C. Rouquet, and C. Boissier, Spatial scales of mesoscale variability in the North Atlantic as deduced from Geosat data, J. Geophys. Res., 95(C11), 20,267-20,285, 1990.

Levitus, S., Climatological Atlas of the World Ocean, NOAA Prof. Pap. 13, U.S. Govt. Print. Off., Washington, D. C., 1982.

Matthews, P. E., M. A. Johnson, and J. J. O'Brien, Observation of mesoscale ocean features in the northeast Pacific using Geosat radar altimetry data, J. Geophys. Res., 97(C11), 17,829-17,840, 1992.

Morris, C. S., and S. K. Gill, Evaluation of the TOPEX/POSEIDON altimeter system over the Great Lakes, J. Geophys. Res., 99(C12), 24,527-24,539, 1994.

Physical Oceanography Distributed Active Archive Center (PODAAC), Merged GDR (TOPEX/POSEIDON) Users Handbook, JPL D-11007, Jet Propul. Lab., Pasadena, Calif., 1993.

Seung, Y. H., A buoyancy flux-driven cyclonic gyre in the Labrador Sea, J. Phys. Oceanogr., 17, 134-146, 1987.

Shriver, J. F., M. A. Johnson, and J. J. O'Brien, Analysis of remotely forced oceanic Rossby waves off California, J. Geophys. Res., 96(C1), 749-757, 1991.

Shuhy, J. L., Oceanographic observations North Atlantic ocean station Bravo-Terminal report 1964-1974, Oceanogr. Rep. CG 373-78, U.S. Coast Guard, Washington, D. C., 1978.

Thompson, K. R., J. R. N. Lazier, and B. Taylor, Wind-forced changes in Labrador Current transport, J. Geophys. Res., 91(C12), 14,261$14,268,1986$.

Vazquez, J., R. H. Zlotnicki, and L.-L. Fu, Sea level variabilities in the Gulf Stream between Cape Hatteras and $50^{\circ} \mathrm{W}, J$. Geophys. Res., 95(C10), 17,957-17,964, 1990.

White, W. B., E. P. Stephen, and M. Inoue, Hindcast/forecast of ENSO events based upon the redistribution of observed and model heat content in the western tropical Pacific, 1964-86, J. Phys. Oceanogr., 17, 264-280, 1987.

White, W. B., C. K. Tai, and J. Dimento, Annual Rossby wave characteristics in the California Current region from the GEOSAT Exact Repeat Mission, J. Phys. Oceanogr., 20, 1297-1311, 1990.

G. Han, Coastal Ocean Sciences, Department of Fisheries and Oceans, Bedford Institute of Oceanography, Dartmouth, Nova Scotia, B2Y 4A2 Canada. (e-mail: ghan@emerald.bio.dfo.ca)

M. Ikeda, Graduate School of Environmental Earth Sciences, Hokkaido University, Sapporo, Japan 060.

(Received April 19, 1996; revised August 29, 1996; accepted September 9, 1996.) 